Article

\title{
Lower Temperature Cultures Enlarge the Effects of Vitreoscilla Hemoglobin Expression on Recombinant Pichia pastoris
}

\author{
Jyh-Ming Wu ${ }^{1, *}$, Shin-Yao Wang ${ }^{2}$ and Wei-Chang Fu ${ }^{1}$
}

1 Department of Chemical and Materials Engineering, Chinese Culture University, 55, Hwa-Kang Rd., Yang-Ming-Shan, Taipei 111-14, Taiwan; E-Mail: fu_95244611@yahoo.com.tw

2 Institute of Nanomaterials, Chinese Culture University, 55, Hwa-Kang Rd., Yang-Ming-Shan, Taipei 111-14, Taiwan; E-Mail: alioth77213@hotmail.com

* Author to whom correspondence should be addressed; E-Mail: wzm4@faculty.pccu.edu.tw; Tel.: +886-2-2861-0511 (ext. 33131); Fax: +886-2-2861-4011.

Received: 2 August 2012; in revised form: 19 September 2012 / Accepted: 8 October 2012 / Published: 15 October 2012

\begin{abstract}
An heterologous expression of Vitreoscilla hemoglobin ( $\mathrm{VHb}$ ) for improving cell growth and recombinant protein production has been successfully demonstrated in various hosts, including Pichia pastoris. Lower temperature cultures can enhance target protein production in some studies of $P$. pastoris. In this study, the strategy of combining heterologous $\mathrm{VHb}$ expression and lower temperature cultures in $P$. pastoris showed that final cell density and viability of $\mathrm{VHb}^{+}$strain at $23{ }^{\circ} \mathrm{C}$ were higher than that at $30^{\circ} \mathrm{C}$. In addition, the effects of $\mathrm{VHb}$ expression on recombinant $\beta$-galactosidase production and oxygen uptake rate were also higher at $23{ }^{\circ} \mathrm{C}$ than at $30{ }^{\circ} \mathrm{C}$. Consequently, lower temperature cultures can enlarge $\mathrm{VHb}$ effectiveness on cell performance of $P$. pastoris. This is because $\mathrm{VHb}$ activity obtained at $23{ }^{\circ} \mathrm{C}$ cultures was twofold higher than that at $30{ }^{\circ} \mathrm{C}$ cultures, due to a different heme production. This strategy makes P. pastoris an excellent expression host particularly suitable for increasing the yields of the low-stability and aggregation-prone recombinant proteins.
\end{abstract}

Keywords: Vitreoscilla hemoglobin; lower temperature; Pichia pastoris; AOX 1 promoter; recombinant protein production 


\section{Introduction}

Vitreoscilla hemoglobin ( $\mathrm{VHb}$ ), which is synthesized by the strict aerobic bacterium Vitreoscilla, aids the survival and growth of this organism in oxygen-poor environments. The putative function of $\mathrm{VHb}$ is to trap oxygen at low extracellular concentrations and deliver it to terminal respiratory oxidases that enhance respiratory efficiency and ATP synthesis [1]. Metabolic engineering studies have demonstrated that intracellular expression of $\mathrm{VHb}$ in different hosts, including prokaryotes and eukaryotes, leads to enhanced oxygen availability, increased cell growth, and improved metabolite and recombinant protein production $[2,3]$.

The methylotrophic yeast Pichia pastoris has become a promising host for producing large quantities of heterologous proteins because of the availability of a strong, tightly regulated, methanol-inducible alcohol oxidase (AOX1) promoter. P. pastoris has the potential for high expression levels, efficient extracellular protein secretion, proper protein folding, post-translational modifications such as glycosylation and disulfide bond formation and high cell density growth on a minimal medium $[4,5]$.

$\mathrm{VHb}$ is a suitable oxygen-uptake improving protein for expression in P. pastoris because of its high oxygen trapping and releasing ability, enabling it to satisfy extremely high oxygen demand during fermentations. In our previous study [6], intracellular expression of VHb can improve cell performance and recombinant $\beta$-galactosidase production in $P$. pastoris $\mathrm{VHb}^{+}$strain cultured at $30{ }^{\circ} \mathrm{C}$, under different aeration conditions.

Recently, some studies have reported that lower temperature cultures at $20-25^{\circ} \mathrm{C}$ in $P$. pastoris can improve the target protein production, lower the cell lysis, reduce the release of intracellular proteases to culture medium and decrease the proteolytic activity [7-9]. Therefore, the combinational strategy of $\mathrm{VHb}$ technology and lower temperature technique is worthy for the study of the synergetic effect on cell performance of $P$. pastoris and to determine if $\mathrm{VHb}$ beneficial effect can be enlarged by lower temperature cultures. Based on our results, the proposed strategy is practical and effective.

\section{Results and Discussion}

\subsection{Construction of Recombinant Strains}

A recombinant $P$. pastoris strain capable of cytosolic co-expression of $\mathrm{VHb}$ and $\beta$-galactosidase under the control of AOX1 promoter was constructed in our previous study [6]. Briefly, the $v g b$-bearing $\mathrm{pP}$-SVC plasmid was introduced into $P$. pastoris strain $\mathrm{GS} 115 / \mathrm{Z}_{\mathrm{A}}$ to generate the GS115/Z $\mathrm{Z}_{\mathrm{A}} \mathrm{SVC}$ strain $\left(\mathrm{VHb}^{+}\right.$strain), whereas the control strain $\mathrm{VHb}^{-}$was constructed by transforming the empty vector pPICZA into the GS115/Z $Z_{\mathrm{A}}$ strain. VHb expression was confirmed by Western-blotting analysis and biological activity was verified by CO-difference spectra assay. The results showed that $\mathrm{VHb}$ was functionally expressed in the cytoplasm by $\mathrm{VHb}^{+}$strain [6].

\subsection{Effect of VHb Expression on Biomass at Lower Temperatures}

Cell growth of $\mathrm{VHb}^{+}$and $\mathrm{VHb}^{-}$strains incubated at $250 \mathrm{rpm}$ in shake-flasks under two temperatures of $30{ }^{\circ} \mathrm{C}$ and $23{ }^{\circ} \mathrm{C}$ were compared to study the effects of $\mathrm{VHb}$ expression and lower temperature 
cultures on P. pastoris biomass. As shown in Figure 1A, the two strains growth during the first $48 \mathrm{~h}$ of $30{ }^{\circ} \mathrm{C}$ cultures were almost identical. After glucose as well as ethanol completely depleted (Figure 1B) and then methanol added at $48 \mathrm{~h}$, the differences in cell growth occurred immediately and increased with culture time caused by induced $\mathrm{VHb}$ expression. The maximal biomass of $\mathrm{VHb}^{+}$and $\mathrm{VHb}^{-}$strains reached 13.7 and $11.4 \mathrm{mg}-\mathrm{DCW} / \mathrm{mL}$ respectively, which was enhanced $20 \%$ by the effect of $\mathrm{VHb}$ expression. Both strains also displayed identical cell growth during the first $72 \mathrm{~h}$ of $23{ }^{\circ} \mathrm{C}$ cultures, thereafter, their growth differences significantly increased with time. $\mathrm{VHb}^{+}$and $\mathrm{VHb}^{-}$strains can grow to maximal values of 16.0 and $11.2 \mathrm{mg}-\mathrm{DCW} / \mathrm{mL}$ respectively, which was a substantial increase of $43 \%$ by $\mathrm{VHb}$ effect. Therefore, $\mathrm{VHb}$ effect on biomass was positive at both temperatures, however, the effect was more pronounced at $23^{\circ} \mathrm{C}$.

Figure 1. Time courses of cell growth $(\mathbf{A})$, glucose concentration $(\mathbf{B}, \mathbf{C})$ and cell viability (D) of Vitreoscilla hemoglobin $(\mathrm{VHb})^{+}$and $\mathrm{VHb}^{-}$strains cultured at two temperatures. Data are the means of three independent replicates. Error bars indicate standard deviations.

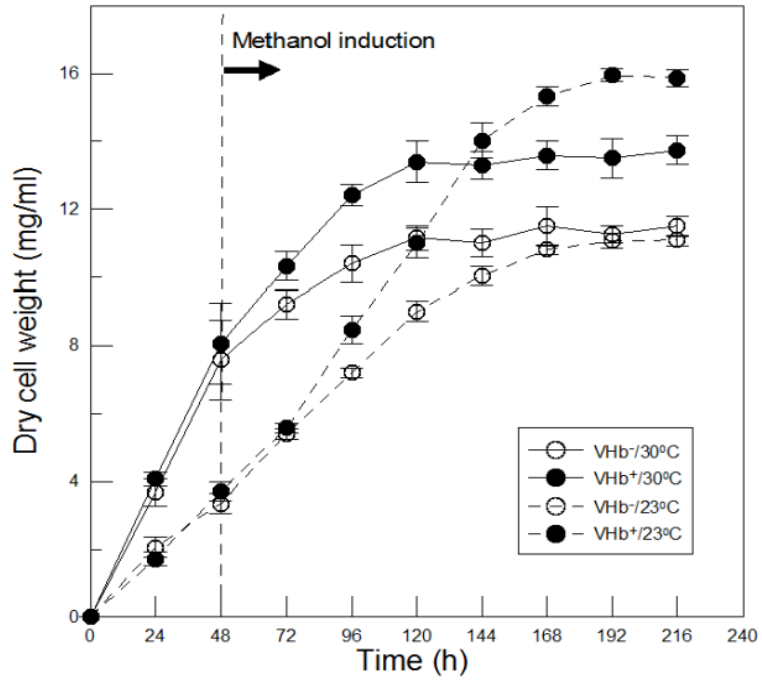

(A)

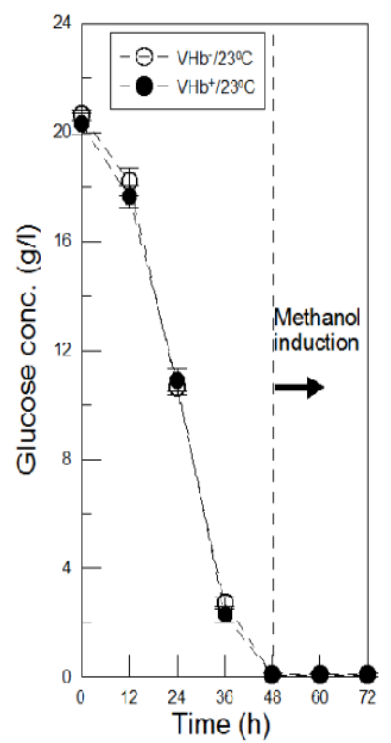

(C)

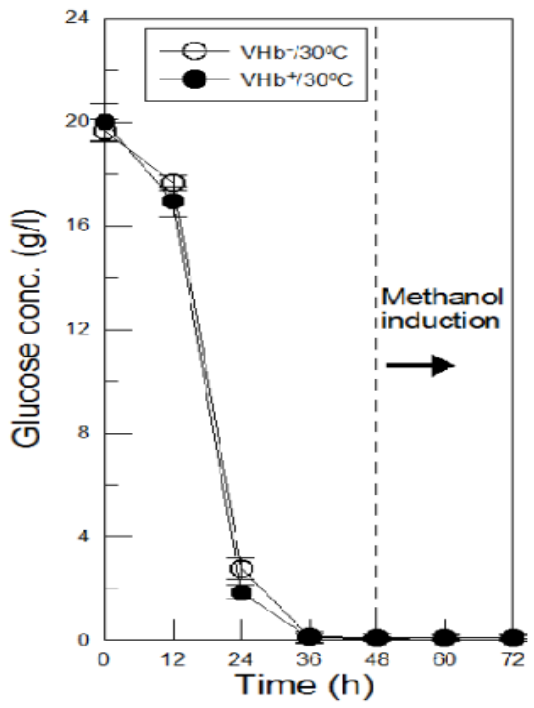

(B)

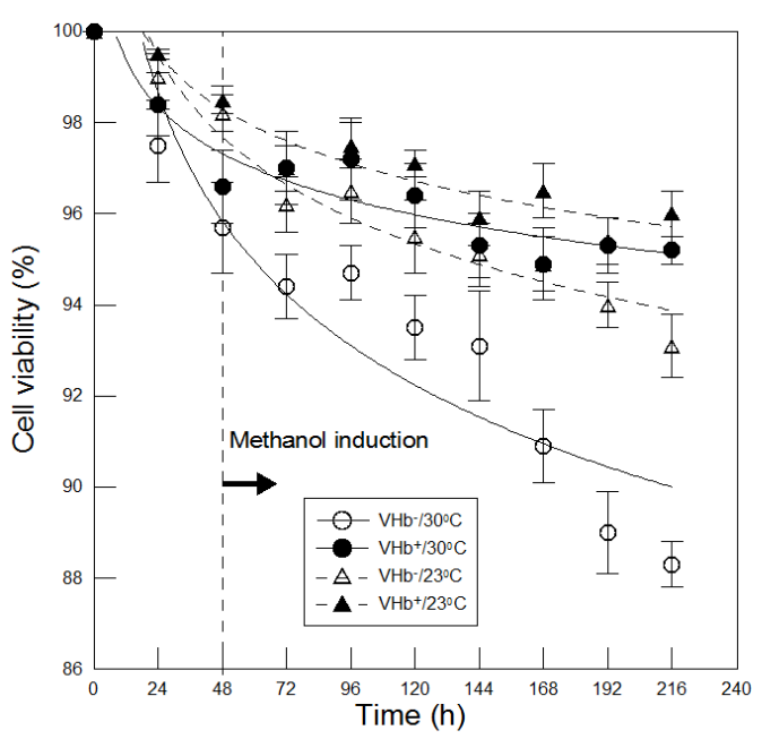

(D) 
Since lower temperature cultures are not favorable for $P$. pastoris growth, the biomass of two strains during the first $72 \mathrm{~h}$ of the $23{ }^{\circ} \mathrm{C}$ cultures were only half of those at $30{ }^{\circ} \mathrm{C}$. The glucose consumption rates of two strains at $23{ }^{\circ} \mathrm{C}$ were also slower than that at $30{ }^{\circ} \mathrm{C}$ (Figure 1B,C). However, $\mathrm{VHb}^{-}$strain cultured at two temperatures can reach the same final cell density with different kinetics. At $30{ }^{\circ} \mathrm{C}$ most of biomass was produced before methanol induction and growth ceased after induction, while at $23{ }^{\circ} \mathrm{C}$ growth continued for a prolonged time. For $\mathrm{VHb}^{+}$strain, growth was faster after induction than for the $\mathrm{VHb}^{-}$strain at $30{ }^{\circ} \mathrm{C}$ as well as at $23{ }^{\circ} \mathrm{C}$, leading to more biomass produced. After $144 \mathrm{~h}$ of $23{ }^{\circ} \mathrm{C}$ cultures cell density of $\mathrm{VHb}^{+}$strain surpassed itself at $30{ }^{\circ} \mathrm{C}$, and at the end of cultures biomass was increased by $17 \%$. Thus, $\mathrm{VHb}$ expression in P. pastoris at lower temperatures can further enhance final cell density. Additionally, growth phase was prolonged significantly by $\mathrm{VHb}$ expression, resulting in enhanced biomass accumulation. This implies that substrates of glucose and methanol were used with better efficiency as to increasing the yield coefficient $Y x / s$, since no remaining substrates concentrations were detected at the end of cultures.

The viabilities of $\mathrm{VHb}^{+}$and $\mathrm{VHb}^{-}$strains at both temperatures were also compared. As shown in Figure 1D, the differences in the viabilities of two strains increased with culture time at both temperatures. The decreasing rates of both strains were slower at $23{ }^{\circ} \mathrm{C}$ and eventually obtained higher viabilities than that at $30{ }^{\circ} \mathrm{C}$. At $23{ }^{\circ} \mathrm{C}$ the viabilities of $\mathrm{VHb}^{+}$and $\mathrm{VHb}^{-}$strains at the end of $216 \mathrm{~h}$ of cultures were $96.0 \%$ and $93.1 \%$ respectively, whereas at $30{ }^{\circ} \mathrm{C}$ they were $95.2 \%$ and $88.4 \%$ respectively. Evidently, $\mathrm{VHb}$ expression can benefit the viability at both temperatures. Additionally, the effect of lower temperature cultures on cell viability was higher in $\mathrm{VHb}^{-}$strain than in $\mathrm{VHb}^{+}$strain. This is due to the viability of $\mathrm{VHb}^{+}$strain was already over $95 \%$, thus a further increase was more difficult. Lower temperature cultures can reduce cell death as to increase cell viability in this study. The phenomenon is also observed in other $P$. pastoris studies [10,11], probably because AOX1 activity is higher at lower temperatures so that the toxicity of methanol to cells can be reduced [8].

\subsection{Analysis of VHb Protein at Two Temperatures}

It proved worthwhile to investigate why $\mathrm{VHb}$ effect on biomass was higher at $23{ }^{\circ} \mathrm{C}$ than at $30{ }^{\circ} \mathrm{C}$. First, $\mathrm{VHb}$ expression levels were analyzed. Cells were harvested at the end of $216 \mathrm{~h}$ of cultures and adjusted to the same $\mathrm{OD}_{600}$ before being disrupted. Western-blotting technique was then used to confirm the expressed protein and evaluate protein expression levels. Unexpectedly, the levels of expressed $\mathrm{VHb}$ polypeptides (globin portion) at two temperatures were nearly equal (Figure 2). This finding differed from what we first thought, namely, $23{ }^{\circ} \mathrm{C}$ cultures could enhance $\mathrm{VHb}$ expression (primarily based on the studies reporting that lower temperature cultures can improve recombinant protein expression in P. pastoris [10-12]) as to increase $\mathrm{VHb}$ effect on biomass. Evidently, $\mathrm{VHb}$ expression cannot be increased by lower temperature cultures.

Subsequently, VHb activity was determined using the CO-difference spectra assay under $25{ }^{\circ} \mathrm{C}$. Samples were reduced with dithionite in the presence and absence of CO. Then the treated samples were scanned on a spectrophotometer. As seen in Figure $3 \mathrm{~A}$, the difference spectra of $\mathrm{VHb}^{+}$ strain showed a peak in the Soret region at $419 \mathrm{~nm}$, which is characteristic of active VHb. Suddenly, $\mathrm{VHb}$ activity obtained at the end of $216 \mathrm{~h}$ of $23{ }^{\circ} \mathrm{C}$ cultures was $17.8 \mathrm{nmol} / \mathrm{g}-\mathrm{DCW}$, which was approximately twofold higher than that obtained at $30{ }^{\circ} \mathrm{C}$ (Figure $3 \mathrm{~B}$ ). The finding was in favorable 
agreement with the fact that the color of total cell lysates of $\mathrm{VHb}^{+}$strain cultured at $23{ }^{\circ} \mathrm{C}$ was redder than itself at $30^{\circ} \mathrm{C}$ (Figure 3C). This implies that at $30{ }^{\circ} \mathrm{C}$ probably there was a significant fraction of $\mathrm{VHb}$ that lacked the essential cofactor of heme group. As a result, lower temperature cultures cannot improve $\mathrm{VHb}$ expression but can significantly increase $\mathrm{VHb}$ activity.

Figure 2. Western-blotting analysis of proteins expressed by $\mathrm{VHb}^{+}$and $\mathrm{VHb}^{-}$strains at the end of $216 \mathrm{~h}$ of culture under two temperatures.

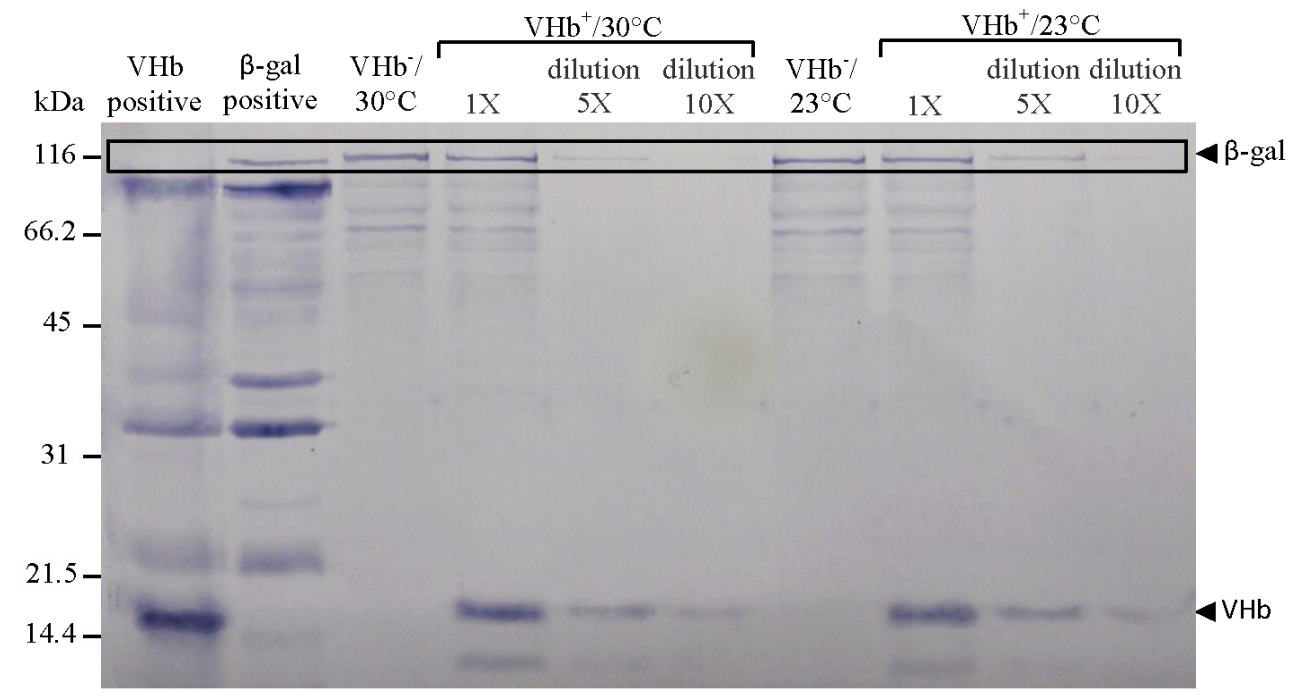

Figure 3. Analysis of $\mathrm{VHb}$ expression at the end of $216 \mathrm{~h}$ of culture at two temperatures. (A) CO-difference spectra of crude protein extracts. The difference in absorbance between CO-dithionite-reduced and dithionite-reduced samples is plotted; (B) Bar chart of $\mathrm{VHb}$ activity. Data are the means of three independent replicates. Error bars indicate standard deviations; (C) Total cell lysates after ultrasonicated treatment. The detailed procedure is described in Section 3.4; (D) Visible absorption spectra of crude VHb extracts in the oxygenated (untreated samples) and deoxygenated (dithionite reduced samples) forms.

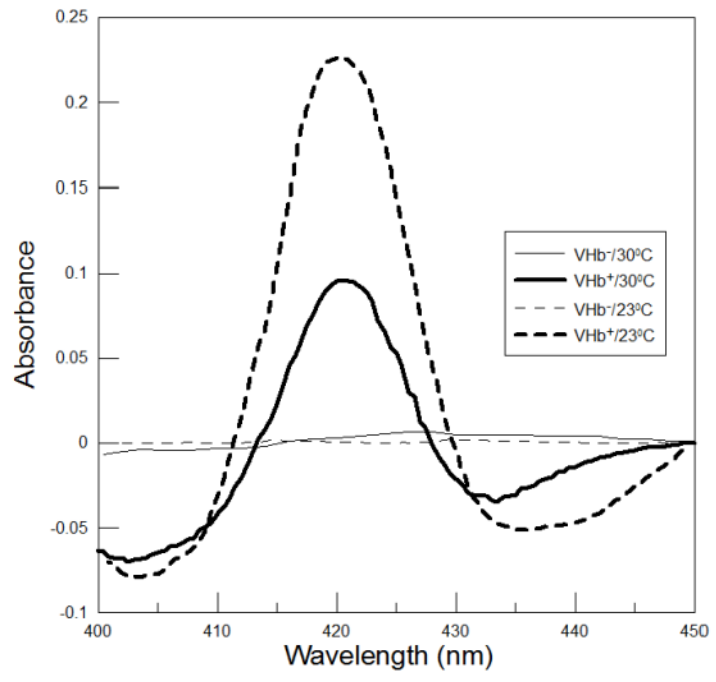

(A)

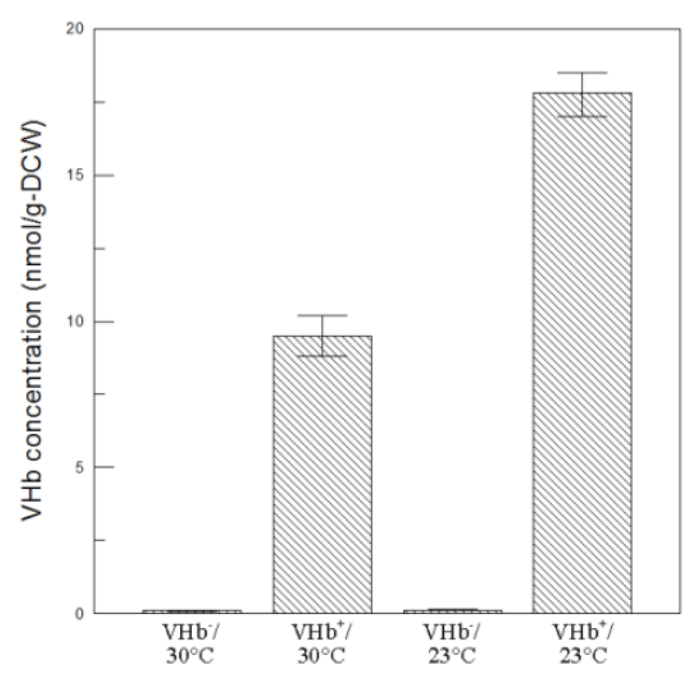

(B) 
Figure 3. Cont.

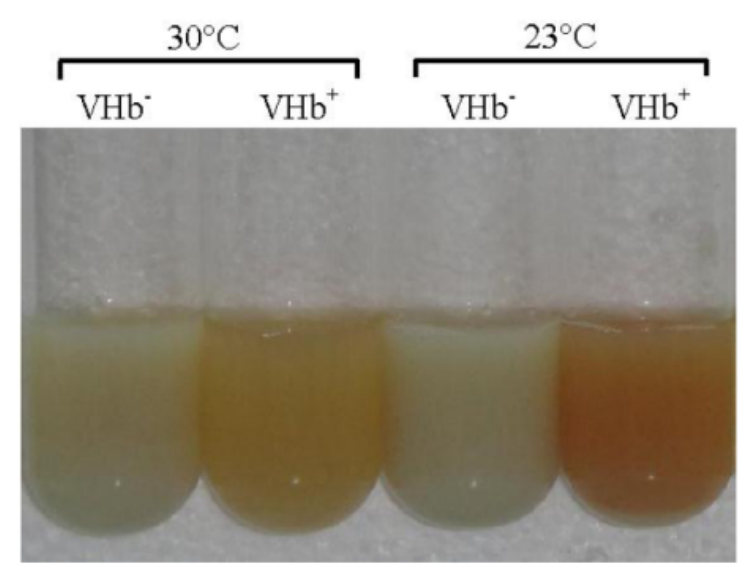

(C)

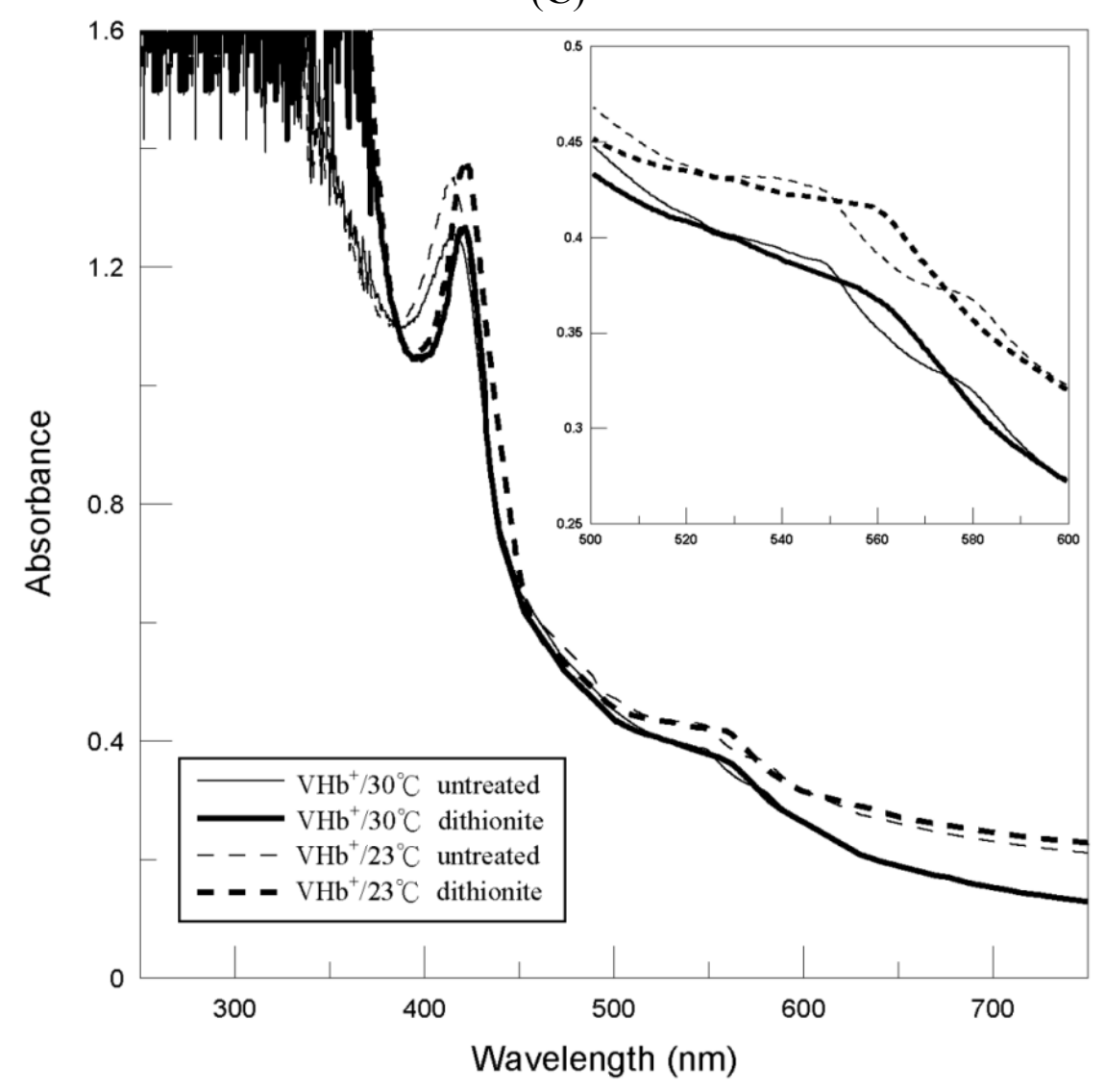

(D)

In addition, the $\mathrm{VHb}$ expressed at both temperatures exhibited a spectrum characteristic of the oxygenated form. The phenomenon was also observed previously in Vitreoscilla [13] and E. coli [14] that the expressed $\mathrm{VHb}$ existed in the physiologically active ferrous oxygenated form. In our study, the spectrum of the oxygenated $\mathrm{VHb}$ obtained from two temperature cultivations had a Soret peak at $415 \mathrm{~nm}$ and $\alpha$ and $\beta$ bands at 580 and $550 \mathrm{~nm}$, respectively (Figure 3D), which represented the hexacoordinated ferrous heme state. After reduced with dithionite (the deoxygenated form) the Soret peak shifted to $425 \mathrm{~nm}$ and one broad peak at $562 \mathrm{~nm}$ replaced the $\alpha$ and $\beta$ bands, indicating the pentacoordinated ferrous heme state. The heights of $\alpha$ and $\beta$ peaks obtained from $23{ }^{\circ} \mathrm{C}$ cultivation were more intense than that at $30^{\circ} \mathrm{C}$. 
To clarify if the above results could be caused by the $\mathrm{VHb}$ reactivity being more favorable only at lower temperatures, $\mathrm{VHb}$ activity was determined at different reaction temperatures. The results shown in Figure 4A indicated that $\mathrm{VHb}$ activity obtained at two temperatures cultures did not obviously change within the assay temperatures between $30{ }^{\circ} \mathrm{C}$ and $23{ }^{\circ} \mathrm{C}$, thus this reason can be ruled out. Additionally, the exogenous provision of $\mathrm{VHb}$ to the assay conditions of the oxygen-consuming enzyme (cytochrome c oxidase) was also carried out to examine if $\mathrm{VHb}$ can increase the oxidase activity. First, the cleared lysates of $\mathrm{VHb}^{+}$cells were incubated at $42{ }^{\circ} \mathrm{C}$ for $6 \mathrm{~h}$ to inactivate cytochrome c oxidase activity. Since cytochrome c oxidase is sensitive to temperatures, whereas $\mathrm{VHb}$ can endure temperatures of up to $80^{\circ} \mathrm{C}$ [15]. The VHb-containing samples were then added to the cleared lysates of freshly disrupted $\mathrm{VHb}^{-}$cells to measure cytochrome c oxidase activity. As shown in Figure 4B, VHb-containing samples obtained at $23{ }^{\circ} \mathrm{C}$ cultures increased cytochrome c oxidase activity by $0.08 \mathrm{nmol} \mathrm{min}{ }^{-1} \mathrm{~mL}^{-1}$, which was twice that obtained at $30{ }^{\circ} \mathrm{C}$ cultures. The result was consistent with that shown in Figure 3 and confirmed again that VHb activity obtained at $23{ }^{\circ} \mathrm{C}$ cultures was twofold higher than that at $30{ }^{\circ} \mathrm{C}$ cultures. It has been proven that $\mathrm{VHb}$ can improve respiratory efficiency and ATP synthesis in recombinant hosts [1]. Due to twofold VHb activity achieved, it is reasonable to obtain more biomass and higher viability by $\mathrm{VHb}^{+}$strain at $23{ }^{\circ} \mathrm{C}$ than at $30^{\circ} \mathrm{C}$.

Figure 4. (A) The effect of assay temperature on VHb activity. (B) The effect of VHb addition on cytochrome $\mathrm{c}$ oxidase activity. The cleared lysates of freshly disrupted $\mathrm{VHb}^{-}$ cells was used as a control. Data are the means of three independent replicates. Error bars indicate standard deviations.

A

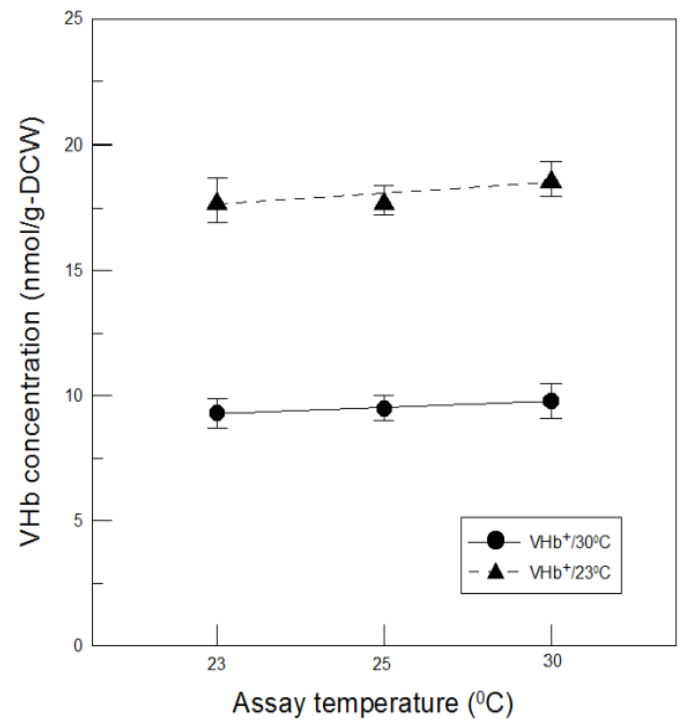

B

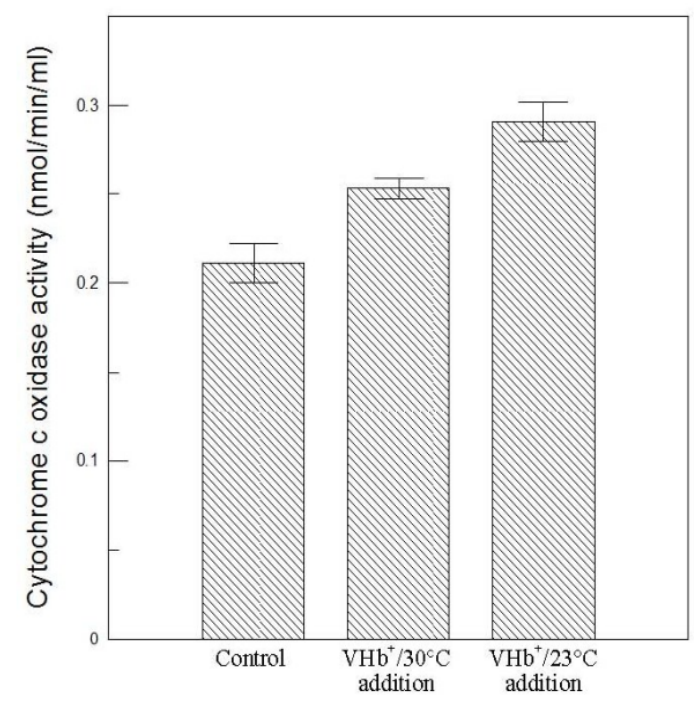

Our results showed that $\mathrm{VHb}$ expression level at $23{ }^{\circ} \mathrm{C}$ was equal to that at $30{ }^{\circ} \mathrm{C}$, but $\mathrm{VHb}$ activity obtained at $23{ }^{\circ} \mathrm{C}$ was twofold higher than that at $30^{\circ} \mathrm{C}$. A similar phenomenon has also been reported in $E$. coli where total globin protein synthesis was barely affected by reducing the temperature from $30{ }^{\circ} \mathrm{C}$ to $26^{\circ} \mathrm{C}$, whereas lower temperature cultures produced a twofold higher soluble $\mathrm{rHb} 1.1$ than higher temperature cultures did [16]. A significant difference between active VHb at $23{ }^{\circ} \mathrm{C}$ and $30{ }^{\circ} \mathrm{C}$ could be caused by improper $\mathrm{VHb}$ folding that lower temperature cultures can reduce protein synthesis 
rate, improve protein folding, and increase protein solubility, or due to inadequate heme incorporation that lower temperature cultures could favor heme biosynthesis so that improve heme incorporation, folding, and subunit assembly. In order to determine exactly why in the difference, the exogenous provision of hemin to $30^{\circ} \mathrm{C}$ culture broth of $\mathrm{VHb}^{+}$strain was performed to examine if the availability of heme is lower at $30{ }^{\circ} \mathrm{C}$ in P. pastoris. As shown in Figure $5 \mathrm{~A}, \mathrm{VHb}$ activity of $\mathrm{VHb}^{+}$strain at the end of $216 \mathrm{~h}$ of $30^{\circ} \mathrm{C}$ cultures increased with hemin concentration and saturated at $200 \mathrm{nM}$ hemin supplement, which was the same level as that of $23{ }^{\circ} \mathrm{C}$ cultures $(17.8 \mathrm{nmol} / \mathrm{g}-\mathrm{DCW})$. This reveals that the amount of heme in P. pastoris at $30{ }^{\circ} \mathrm{C}$ was lower than that at $23{ }^{\circ} \mathrm{C}$, resulting in lower $\mathrm{VHb}$ activity at $30{ }^{\circ} \mathrm{C}$ than $23{ }^{\circ} \mathrm{C}$. Therefore, a different heme production in P. pastoris caused this twofold difference between active $\mathrm{VHb}$ at $23{ }^{\circ} \mathrm{C}$ and $30{ }^{\circ} \mathrm{C}$. In addition, a similar effect of hemin on final cell concentration was observed (Figure 5B). Increase of $\mathrm{VHb}$ activity caused by the exogenous provision of hemin also improved final cell concentration, and the final biomass of $30^{\circ} \mathrm{C}$ culture supplemented with $200 \mathrm{nM}$ hemin was close to that of $23{ }^{\circ} \mathrm{C}$ culture.

Figure 5. The effects of exogenous provision of hemin on $\mathrm{VHb}$ activity (A) and cell concentration $(\mathbf{B})$ of $\mathrm{VHb}^{+}$strain at the end of $216 \mathrm{~h}$ of $30{ }^{\circ} \mathrm{C}$ cultures. Data are the means of three independent replicates. Error bars indicate standard deviations.

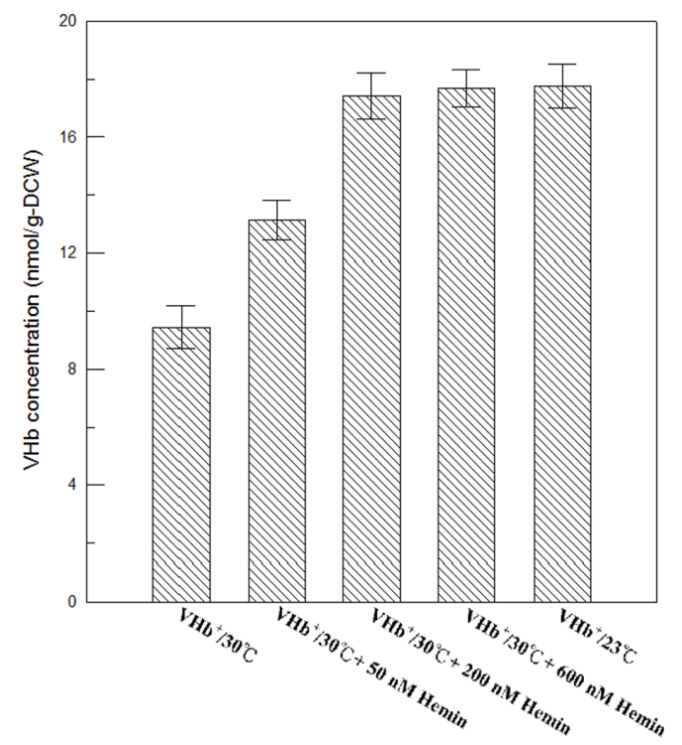

(A)

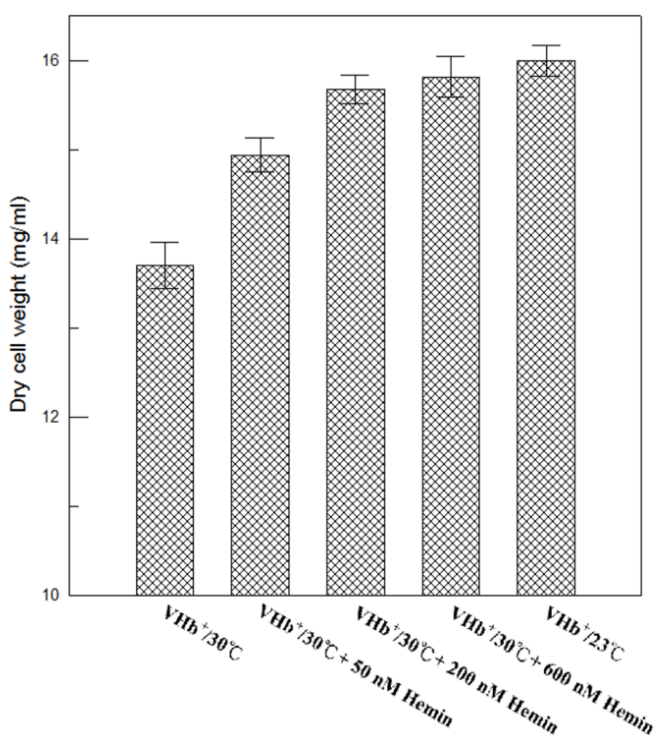

(B)

Lower temperature cultures can increase the availability of oxygen and ATP in P. pastoris. Evidences of higher intracellular ATP levels and increased the ATP regeneration rates [17] were obtained at lower temperature cultures. The saturated dissolved oxygen concentration of YPD medium at $23{ }^{\circ} \mathrm{C}$ is $7.12 \mathrm{ppm}$, which is $17 \%$ higher than that at $30{ }^{\circ} \mathrm{C}(6.08 \mathrm{ppm})$. Increased amounts of oxygen and ATP could affect the flux of several important biosynthetic routes in P. pastoris. Increased oxygen concentration can improve the respiration rate and thereby enhanced the oxygen uptake rates (Figure 7). Oxygen tension also influences the folding and assembly of hemeproteins by affecting the availability or redox state of heme. In addition, oxygen is required for two steps in heme biosynthesis, the formation of protoporphyrinogen IX by coproporphyrinogen III oxidase, and the formation of protoporphyrin IX by protoporphyrinogen IX oxidase. The step catalyzed by coproporphyrinogen III 
oxidase is rate limiting [18]. VHb is a homodimeric protein, and each protomer incorporates a heme prosthetic group in its native state. $\mathrm{VHb}$ requires the presence of adequate heme production during $\mathrm{VHb}$ protein biosynthesis and folding. Higher amounts of heme could be produced at $23{ }^{\circ} \mathrm{C}$ than at $30{ }^{\circ} \mathrm{C}$ because lower temperature cultures can increase the availability of dissolved oxygen and ATP, which are used in several steps of heme biosynthesis [18]. Higher availability of heme could favor heme incorporation, folding, and subunit assembly of $\mathrm{VHb}$ protein. As a result, more holo $\mathrm{VHb}(\mathrm{VHb}$ protein carrying heme) could be obtained at $23{ }^{\circ} \mathrm{C}$ and resulted in twofold higher $\mathrm{VHb}$ activity than that at $30{ }^{\circ} \mathrm{C}$. However, more apoVHb (VHb protein lacking heme) could be produced at $30{ }^{\circ} \mathrm{C}$ due to lower availability of heme. The statement also can be confirmed by the result of Figure $3 \mathrm{C}$ that more VHb missing heme at $30{ }^{\circ} \mathrm{C}$ resulted in a great difference in red color compared to that of $23{ }^{\circ} \mathrm{C}$.

\subsection{Effect of VHb Expression on Recombinant $\beta$-Galactosidase Production at Lower Temperatures}

The differences in recombinant $\beta$-galactosidase production between $\mathrm{VHb}^{+}$and $\mathrm{VHb}^{-}$strains at two temperatures were compared. As shown in Figure 6, before induction no $\beta$-galactosidase activity was detected in both strains at two temperatures. However, after the absence of glucose (Figure 1B,C) and thereby methanol induction at $48 \mathrm{~h}$ of cultures, $\beta$-galactosidase began to express. At $30{ }^{\circ} \mathrm{C}$ $\beta$-galactosidase of $\mathrm{VHb}^{-}$strain was produced immediately and increased with time, leading to a maximal value of $36,000 \mathrm{U} / \mathrm{mL}$ achieved at the end of $216 \mathrm{~h}$ of cultures. While $\beta$-galactosidase of $\mathrm{VHb}^{+}$strain differed from that of $\mathrm{VHb}^{-}$strain. In the early methanol induction phase, $\beta$-galactosidase production of $\mathrm{VHb}^{+}$strain was slower than that of $\mathrm{VHb}^{-}$strain. This could be since recombinant $\mathrm{VHb}$ protein was co-induced by methanol in $\mathrm{VHb}^{+}$strain; $\mathrm{VHb}$ consumed some of cellular resources that could be used for $\beta$-galactosidase biosynthesis. However, expressed $\mathrm{VHb}$ protein could compensate $\mathrm{VHb}^{+}$strain for improving $\beta$-galactosidase production. Therefore, after $120 \mathrm{~h}$ of cultures $\beta$-galactosidase production of $\mathrm{VHb}^{+}$strain exceeded that of $\mathrm{VHb}^{-}$strain and then reached a maximal activity of $40,000 \mathrm{U} / \mathrm{mL}$ at the end of cultures, which was enhanced $11 \%$ by $\mathrm{VHb}$ effect.

Figure 6. Time courses of total $\beta$-galactosidase activity by $\mathrm{VHb}^{+}$and $\mathrm{VHb}^{-}$strains cultured at two temperatures. Data are the means of three independent replicates. Error bars indicate standard deviations.

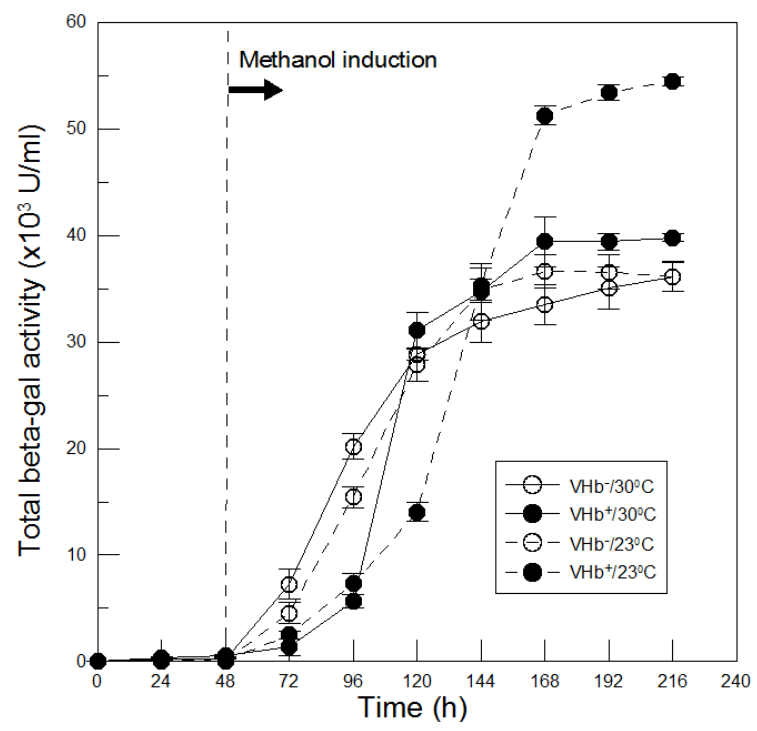


$\beta$-Galactosidase production of $\mathrm{VHb}^{-}$strain at $23{ }^{\circ} \mathrm{C}$ was analogous to itself at $30{ }^{\circ} \mathrm{C}$ and their maximal activities were nearly equivalent. This indicates that $\beta$-galactosidase produced by $\mathrm{VHb}^{-}$strain was independent of culture temperatures, which differed from some previous studies reporting that lower temperature cultures can improve target protein production in P. pastoris [10-12]. Therefore, the effect of lower temperature cultures on recombinant protein production depends on different target proteins. Comparing $\beta$-galactosidase produced at $23{ }^{\circ} \mathrm{C}$ by two strains, $\beta$-galactosidase production of $\mathrm{VHb}^{+}$strain was also slower in the early methanol induction phase due to co-induced two proteins as mentioned above. Later, however, $\mathrm{VHb}$ effect significantly accelerated $\beta$-galactosidase production and eventually reached a maximal activity of $55,000 \mathrm{U} / \mathrm{mL}$, which was $50 \%$ much higher than that of $\mathrm{VHb}^{-}$strain. Additionally, after $144 \mathrm{~h}$ of cultures $\beta$-galactosidase production of $\mathrm{VHb}^{+}$strain at $23{ }^{\circ} \mathrm{C}$ surpassed itself at $30{ }^{\circ} \mathrm{C}$, and finally obtained an increase of $38 \%$ at the end of cultures. This enhancement production of $\beta$-galactosidase is not due to lower temperature cultures improving $\beta$-galactosidase production but caused by twofold $\mathrm{VHb}$ activity obtained at $23{ }^{\circ} \mathrm{C}$ cultures.

The results demonstrated that $23{ }^{\circ} \mathrm{C}$ cultures further increased $\mathrm{VHb}$ activity as to enhance $\mathrm{VHb}$ effect on $\beta$-galactosidase production as well as on biomass. For various proteins expression in different hosts, culture temperatures cannot usually satisfy both the biomass and protein expression simultaneously. But it can be achieved in this study by culturing P. pastoris at $23{ }^{\circ} \mathrm{C}$ and obtained a significant higher biomass and $\beta$-galactosidase production than that at $30{ }^{\circ} \mathrm{C}$, primarily due to $\mathrm{VHb}$ function.

\subsection{Effect of $V H b$ Expression on Oxygen Uptake Rates at Lower Temperatures}

$\mathrm{VHb}^{+}$strain capable of higher biomass and $\beta$-galactosidase production implies that it could have a higher oxygen uptake rate. To explore this possibility, the specific oxygen uptake rates (SOURs) were measured. As shown in Figure 7, SOURs of both strains at two temperatures before methanol induction exhibited no obvious differences (around $3.8 \mathrm{O}_{2} \mathrm{mg} \mathrm{min} \mathrm{g}^{-1} \mathrm{gCW}^{-1}$ ). After induction, however, all SOURs rose to peak values of much higher than $3.8 \mathrm{O}_{2} \mathrm{mg} \mathrm{min}^{-1} \mathrm{~g}-\mathrm{DCW}^{-1}$ due to an increased oxygen demand from cell growth and methanol metabolization, which is a high oxygen-consuming process. SOURs of $\mathrm{VHb}^{-}$strain cultured at $30{ }^{\circ} \mathrm{C}$ and $23{ }^{\circ} \mathrm{C}$ increased from 3.8 before induction to 4.4 and $4.7 \mathrm{O}_{2} \mathrm{mg} \mathrm{min}^{-1} \mathrm{~g}-\mathrm{DCW}^{-1}$ after induction, respectively. While that of $\mathrm{VHb}^{+}$strain rose respectively to 5.6 and $6.3 \mathrm{O}_{2} \mathrm{mg} \mathrm{min}^{-1} \mathrm{~g}-\mathrm{DCW}^{-1}$. The considerably higher increases in $\mathrm{VHb}^{+}$strain than $\mathrm{VHb}^{-}$strain were probably caused by $\mathrm{VHb}$ expression improving oxygen utilization and respiratory efficiency. SOURs of $\mathrm{VHb}^{+}$strain at $30{ }^{\circ} \mathrm{C}$ and $23{ }^{\circ} \mathrm{C}$ were respectively $27 \%$ and $34 \%$ higher than that of $\mathrm{VHb}^{-}$strain, indicating that $\mathrm{VHb}$ effect on SOURs was beneficial at both temperatures but higher at $23{ }^{\circ} \mathrm{C}$. The VHb-expressing strain with a higher oxygen demand has also been reported previously [19-21].

Moreover, after induction $\mathrm{VHb}^{-}$strain had a higher SOUR at $23{ }^{\circ} \mathrm{C}$ than at $30{ }^{\circ} \mathrm{C}$, suggesting that cells at $23{ }^{\circ} \mathrm{C}$ demonstrated higher respiratory efficiency and metabolic activity. This is because the oxygen-consuming enzyme AOX1 activity is higher at lower temperatures [12], which thus can reduce the toxicity of methanol to cells and thereby increase cell viability, as shown in Figure 1D. The phenomenon was also observed in $\mathrm{VHb}^{+}$strain but its SOUR increase $\left(0.56 \mathrm{O}_{2} \mathrm{mg} \mathrm{min}^{-1} \mathrm{~g}-\mathrm{DCW}^{-1}\right)$ 
was twice as that of $\mathrm{VHb}^{-}$strain $\left(0.25 \mathrm{O}_{2} \mathrm{mg} \mathrm{min}^{-1} \mathrm{~g}-\mathrm{DCW}^{-1}\right)$, which was likely caused by twofold $\mathrm{VHb}$ activity obtained at $23{ }^{\circ} \mathrm{C}$ cultures.

Overall, $\mathrm{VHb}^{+}$strain had a higher SOUR at $23{ }^{\circ} \mathrm{C}$ than at $30^{\circ} \mathrm{C}$, indicating that cell performance of $\mathrm{VHb}^{+}$strain was better at $23{ }^{\circ} \mathrm{C}$. It can reasonably explain why $\mathrm{VHb}^{+}$strain at $23{ }^{\circ} \mathrm{C}$ had a higher final cell density, cell viability, and $\beta$-galactosidase production. Consequently, lower temperature cultures can enlarge $\mathrm{VHb}$ effect on cell performance of $P$. pastoris.

Figure 7. Comparison of specific oxygen uptake rates (SOURs) of $\mathrm{VHb}^{+}$and $\mathrm{VHb}^{-}$strains cultured at two temperatures. The values for before induction were measured after $24 \mathrm{~h}$ of culture, and the values for after induction were the maximal values measured after induction. Data are the means of three independent replicates. Error bars indicate standard deviations.

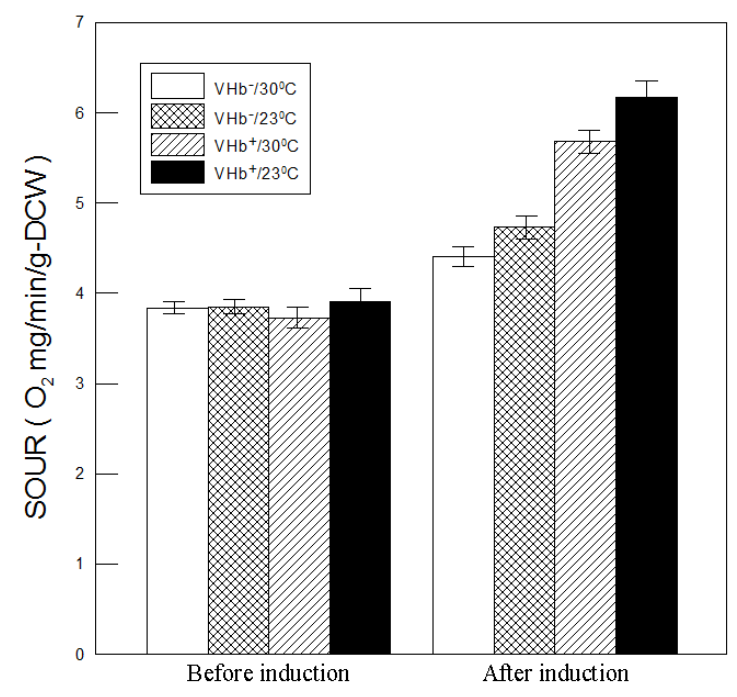

\section{Experimental Section}

\subsection{Strains and Culture Conditions}

P. pastoris strain $\mathrm{GS} 115 / \mathrm{Z}_{\mathrm{A}}$ (GS115/ $\mathrm{His}^{+} \mathrm{Mut}^{+} / \beta$-gal) was purchased from Invitrogen. The recombinant $P$. pastoris strain $\mathrm{GS} 115 / \mathrm{Z}_{\mathrm{A}} \mathrm{SVC}\left(\mathrm{GS} 115 / \mathrm{His}^{+} \mathrm{Mut}^{+} / \beta\right.$-gal $\mathrm{VHb} ; \mathrm{VHb}^{+}$strain) that produces cytosolic $\beta$-galactosidase and $\mathrm{VHb}$ both under the control of AOX1 promoter was obtained from our previous study [6]. Shake-flask batch cultures were performed at two temperatures of $30{ }^{\circ} \mathrm{C}$ and $23{ }^{\circ} \mathrm{C}$ to study the effects of $\mathrm{VHb}$ expression and lower temperature cultures on cell performance of $P$. pastoris. Recombinant strains were incubated at $250 \mathrm{rpm}$ in $250-\mathrm{mL}$ shake flasks containing $50 \mathrm{~mL}$ of YPD medium (1\% yeast extract, $2 \%$ peptone, $2 \%$ dextrose). After glucose as well as ethanol completely exhausted at $48 \mathrm{~h}$ of culture, methanol was added to culture medium to a final concentration of $0.5 \%(v / v)$ every $24 \mathrm{~h}$ to induce both $\mathrm{VHb}$ and $\beta$-galactosidase expression. The concentration of glucose and ethanol was determined using HPLC method (Acme 9000 HPLC system, Younglin Instrument Co., Anyang, Korea). Samples were collected at regular intervals to determine protein activity and cell growth, which were monitored by measuring the optical density at $600 \mathrm{~nm}$ $\left(\mathrm{OD}_{600}\right)$ using a spectrophotometer (Varian Cary $50 \mathrm{UV} / \mathrm{Vis}$, Walnut Creek, CA, USA). The biomass was also determined gravimetrically by performing a dry cell weight (DCW) measurement. 


\subsection{Measurement of Cell Viability}

Cell viability was measured using the methylene blue dye exclusion technique, as previously described by Wang et al. [10]. Culture samples were obtained at regular intervals, and a suitably diluted cell suspension was mixed with an equal volume of methylene blue dye solution, containing $0.01 \%(w / v)$ methylene blue and $2 \%(w / v)$ tri-sodium citrate dihydrate in phosphate-buffered saline solution (137 mM NaCl, $2.7 \mathrm{mM} \mathrm{KCl,} 10 \mathrm{mM} \mathrm{Na} 2 \mathrm{HPO}_{4}, 1.8 \mathrm{mM} \mathrm{KH}_{2} \mathrm{PO}_{4}$; $\mathrm{pH}$ 7.4). Samples were then mounted on a hemocytometer under an optical microscope (Olympus CX31, Tokyo, Japan), and the percentage of live cells in the total population was calculated. The cells that had absorbed methylene blue and appeared dark blue were considered dead, while those that appeared translucent were regarded as live.

\subsection{Measurement of Oxygen Uptake Rate}

The oxygen uptake rate (OUR) was determined using the dynamic gassing-out method described by Urgun-Demirtas et al. [22]. Recombinant P. pastoris strains were harvested at regular intervals using centrifugation at $6000 \mathrm{~g}$ for $10 \mathrm{~min}$. Cell pellets were washed twice with the air-saturated YPD medium and then resuspended in $80 \mathrm{~mL}$ of the same medium. A magnetic impeller was installed in the bottle of reaction chamber, which was tightly sealed using an oxygen probe (YSI Model 5100 dissolved oxygen meter, Yellow Springs, OH, USA). Time course of the decrease in the dissolved oxygen concentration was recorded, and the slope of dissolved oxygen versus time plot was used to determine the OUR. The specific oxygen uptake rate (SOUR), defined as the ratio of OUR to DCW, was expressed as milligrams of oxygen consumed per minute per g-DCW.

\subsection{Analysis of Protein Expression and Activity}

Ortho-nitrophenyl- $\beta$-D-galactopyranoside (ONPG, Sigma, St. Louis, MO, USA) was used as the reaction substrate to measure $\beta$-galactosidase activity. Recombinant $P$. pastoris cells were first permeabilized with $40 \%$ isopropanol [23], and $\beta$-galactosidase activity was then assayed using the procedure described in the Pichia Expression Kit (Invitrogen, Carlsbad, CA, USA). One enzyme unit is defined as the quantity of enzyme that catalyzes the liberation of $1 \mu \mathrm{mol}$ of ortho-nitrophenol from ONPG per minute under the assay conditions.

To determine $\mathrm{VHb}$ activity, the carbon monoxide (CO)-difference spectra assay of crude protein extract was recorded, as described previously [24]. Cell pellets were harvested using centrifugation at $6000 \mathrm{~g}$ for $10 \mathrm{~min}$ and washed twice with the breaking buffer $(50 \mathrm{mM}$ sodium phosphate $(\mathrm{pH} 7.4)$, $1 \mathrm{mM}$ PMSF, $1 \mathrm{mM}$ EDTA, and 5\% glycerol). The pellets were then resuspended in the same buffer and sonicated in an ice bath using an ultrasonifier, followed by centrifugation at $12,000 \mathrm{~g}$ for $15 \mathrm{~min}$ to remove cell debris. The supernatants thus obtained were used as the crude protein extracts, which were reduced with sodium dithionite and bubbled with $\mathrm{CO}$ to analyze $\mathrm{VHb}$ activity. The CO-difference spectra were recorded from 400 to $500 \mathrm{~nm}$ using a spectrophotometer (Varian Cary $50 \mathrm{UV} / \mathrm{Vis}$, Walnut Creek, CA, USA). The absorbance of a VHb sample in the sample cuvette that had been bubbled with $\mathrm{CO}$ and an otherwise identical sample of $\mathrm{VHb}$ that had not been bubbled with $\mathrm{CO}$ were recorded, and the difference absorption spectra between $\mathrm{CO}$-dithionite-reduced and dithionite-reduced 
samples were determined. $\mathrm{VHb}$ concentration was calculated using the extinction coefficient $\mathrm{E}_{419-436 \mathrm{~nm}}=274 \mathrm{mM}^{-1} \mathrm{~cm}^{-1}$, as previously described [14].

Cytochrome c oxidase activity was determined using a colorimetric assay based on the oxidation of reduced cytochrome $\mathrm{c}$ to ferricytochrome $\mathrm{c}$ by cytochrome $\mathrm{c}$ oxidase. The reaction can be followed by a decrease in the absorbance at $550 \mathrm{~nm}$ under the following conditions. Samples were incubated at $25^{\circ} \mathrm{C}$ with $10 \mathrm{mM}$ Tris- $\mathrm{HCl}, \mathrm{pH} 7.0,250 \mathrm{mM}$ sucrose, $120 \mathrm{mM} \mathrm{KCl}$, and $0.01 \mathrm{mM}$ ferrocytochrome c for 5 min with 10-s intervals [25].

The crude protein extracts were analyzed using SDS-PAGE and stained with Coomassie brilliant blue. Proteins that had been separated on a $12 \%$ Tris-glycine gel were transferred to a PVDF membrane (Hybond-P, Amersham Pharmacia, Piscataway, NJ, USA) using electroblotting with a transfer apparatus (Mini Trans-Blot Cell, Bio-Rad, Hercules, CA, USA) for Western- blotting analysis. After blotting, the PVDF membrane was soaked with the blocking buffer $(5 \% \mathrm{w} / v$ skimmed milk powder in Tris-buffered saline) and treated with the rabbit anti-VHb antibody and mouse anti- $\beta$-galactosidase antibody for $2 \mathrm{~h}$. The membrane was then washed three times with TBS, followed by treatment with the goat anti-rabbit and goat anti-mouse secondary antibody for $2 \mathrm{~h}$, both conjugated with alkaline phosphatase. The membrane was again washed three times with TBS, and the image was developed using the Immun-Blot AP kit (Bio-Rad) to detect the expression of $\mathrm{VHb}$ and $\beta$-galactosidase.

\section{Conclusions}

Lower temperature cultures at $23{ }^{\circ} \mathrm{C}$ can enlarge $\mathrm{VHb}$ effect on cell performance of $P$. pastoris in order to obtain a higher final cell density, viability, SOUR and $\beta$-galactosidase production in comparison with $30{ }^{\circ} \mathrm{C}$ cultures, presumably owing to the twofold $\mathrm{VHb}$ activity obtained at $23{ }^{\circ} \mathrm{C}$ cultures. A greater fraction of $\mathrm{VHb}$ inactive at $30{ }^{\circ} \mathrm{C}$, compared with that at $23{ }^{\circ} \mathrm{C}$, was caused by the absence of heme at $30{ }^{\circ} \mathrm{C}$. The strategy of combining heterologous $\mathrm{VHb}$ expression and lower temperature cultures makes $P$. pastoris an excellent expression platform particularly suitable for increasing the yields of the aggregation-prone and low-stability recombinant proteins.

\section{Acknowledgments}

This research study was financially supported by Chinese Culture University and National Science Council of Taiwan (NSC 95-2221-E-034-006).

\section{References}

1. Park, K.W.; Kim, K.J.; Howard, A.J.; Stark, B.C.; Webster, D.A. Vitreoscilla hemoglobin binds to subunit I of cytochrome bo ubiquinol oxidases. J. Biol. Chem. 2002, 277, 33334-33337.

2. Zhang, L.; Li, Y.J.; Wang, Z.N.; Xia, Y.; Chen, W.S.; Tang, K.X. Recent developments and future prospects of Vitreoscilla hemoglobin application in metabolic engineering. Biotechnol. Adv. 2007, 25, 123-136.

3. Wei, X.X.; Chen, G.Q. Applications of the VHb gene vgb for improved microbial fermentation processes. Methods Enzymol. 2008, 436, 269-283. 
4. Macauley-Patrick, S.; Fazenda, M.L.; McNeil, B.; Harvey, L.M. Heterologous protein production using the Pichia pastoris expression system. Yeast 2005, 22, 249-270.

5. Cereghino, J.L.; Cregg, J.M. Heterologous protein expression in the methylotrophic yeast Pichia pastoris. FEMS Microbiol. Rev. 2000, 24, 45-66.

6. Wu, J.M.; Fu, W.C. Intracellular co-expression of Vitreoscilla hemoglobin enhances cell performance and $\beta$-galactosidase production in Pichia pastoris. J. Biosci. Bioeng. 2012, 113, 332-337.

7. Hong, F.; Meinander, N.Q.; Jönsson, L.J. Fermentation strategies for improved heterologous expression of laccase in Pichia pastoris. Biotechnol. Bioeng. 2002, 79, 438-449.

8. Jahic, M.; Wallberg, F.; Bollok, M.; Garcia, P.; Enfors, S.O. Temperature limited fed-batch technique for control of proteolysis in Pichia pastoris bioreactor cultures. Microb. Cell Fact. 2003, 2, doi:10.1186/1475-2859-2-6.

9. Dragosits, M.; Stadlmann, J.; Albiol, J.; Baumann, K.; Maurer, M.; Gasser, B.; Sauer, M.; Altmann, F.; Ferrer, P.; Mattanovich, D. The effect of temperature on the proteome of recombinant Pichia pastoris. J. Proteome Res. 2009, 8, 1380-1392.

10. Wang, Y.; Wang, Z.; Xu, Q.; Du, G.; Hua, Z.; Liu, L.; Li, J.; Chen, J. Lowering induction temperature for enhanced production of polygalacturonate lyase in recombinant Pichia pastoris. Process Biochem. 2009, 44, 949-954.

11. Li, Z.; Xiong, F.; Lin, Q.; d'Anjou, M.; Daugulis, A.J.; Yang, D.S.; Hew, C.L. Low-temperature increases the yield of biologically active herring antifreeze protein in Pichia pastoris. Protein Expr. Purif. 2001, 21, 438-445.

12. Jin, H.; Liu, G.; Dai, K.; Wang, H.; Li, Z.; Shi, Z. Improvement of porcine interferon- $\alpha$ production by recombinant Pichia pastoris via induction at low methanol concentration and low temperature. Appl. Biochem. Biotechnol. 2011, 165, 559-571.

13. Webster, D.A.; Orii, Y. Physiological role of oxygenated cytochrome $o$ : Observations on whole-cell suspensions of Vitreoscilla. J. Bacteriol. 1978, 135, 62-67.

14. Dikshit, K.L.; Webster, D.A. Cloning characterization, and expression of the bacterial globing gene from Vireoscilla in Escherichia coli. Gene 1988, 70, 377-386.

15. Kvist, M.; Ryabova, E.S.; Nordlander, E.; Bülow, L. An investigation of the peroxidase activity of Vitreoscilla hemoglobin. J. Biol. Inorg. Chem. 2007, 3, 324-334.

16. Weickert, M.J.; Pagratis, M.; Curry, S.R.; Blackmore, R. Stabilization of apoglobin by low temperature increases yield of soluble recombinant hemoglobin in Escherichia coli. Appl. Environ. Microb. 1997, 63, 4313-4320.

17. Gao, M.; Dong, S.; Yu, R.; Wu, J.; Zheng, Z.; Shi, Z.; Zhan, X. Improvement of ATP regeneration efficiency and operation stability in porcine interferon- $\alpha$ production by Pichia pastoris under lower induction temperature. Korean J. Chem. Eng. 2011, 28, 1412-1419.

18. Hoffman, M.; Góra, M.; Rytka, J. Identification of rate-limiting steps in yeast heme biosynthesis. Biochem. Biophys. Res. Commun. 2003, 310, 1247-1253.

19. Chen, H.; Chu, J.; Zhang, S.; Zhuang, Y.; Qian, J.; Wang, Y.; Hu, X. Intracellular expression of Vitreoscilla hemoglobin improves $S$-adenosylmethionine production in a recombinant Pichia pastoris. Appl. Microbiol. Biotechnol. 2007, 74, 1205-1212.

20. Li, M.; Wu, J.; Lin, J.; Wei, D. Expression of Vitreoscilla hemoglobin enhances cell growth and dihydroxyacetone production in Gluconobacter oxydans. Curr. Microbiol. 2010, 61, 370-375. 
21. Suthar, D.H.; Chattoo, B.B. Expression of Vitreoscilla hemoglobin enhances growth and levels of $\alpha$-amylase in Schwanniomyces occidentalis. Appl. Microbiol. Biotechnol. 2006, 72, 94-102.

22. Urgun-Demirtas, M.; Pagilla, K.R.; Stark, B. Enhanced kinetics of genetically engineered Burkholderia cepacia: Role of $v g b$ in the hypoxic cometabolism of 2-CBA. Biotechnol. Bioeng. 2004, 87, 110-118.

23. Liu, Y.; Hana, H.; Fujita, Y.; Kondo, A.; Inoue, Y.; Kimura, A.; Fukuda, H. Production of $S$-lactoylglutathione by high activity whole cell biocatalysts prepared by permeabilization of recombinant Saccharomyces cerevisiae with alcohols. Biotechnol. Bioeng. 1999, 64, 54-60.

24. Liu, C.Y.; Webster, D.A. Spectral characteristics and interconversions of the reduced, oxidized, oxygenated forms of purified cytochrome $o$. J. Biol. Chem. 1974, 249, 4261-4266.

25. Queiroga, C.S.; Almeida, A.S.; Alves, P.M.; Brenner, C.; Vieira, H.L. Carbon monoxide prevents hepatic mitochondrial membrane permeabilization. BMC Cell Biol. 2011, 12, doi:10.1186/1471-2121-12-10.

(C) 2012 by the authors; licensee MDPI, Basel, Switzerland. This article is an open access article distributed under the terms and conditions of the Creative Commons Attribution license (http://creativecommons.org/licenses/by/3.0/). 